OPEN ACCESS

Edited by:

Oana Moldovan

Romanian Academy, Romania

Reviewed by:

Chi Xu,

Nanjing University, China Loreta Cornacchia,

Royal Netherlands Institute for Sea

Research (NIOZ), Netherlands

*Correspondence:

Xiaoli Dong

xldong@ucdavis.edu

Specialty section:

This article was submitted to

Biogeography and Macroecology,

a section of the journa

Frontiers in Ecology and Evolution

Received: 06 July 2020

Accepted: 05 October 2020

Published: 22 October 2020

Citation:

Dong X (2020) A Trait-Based Approach to Self-Organized Pattern

Formation in Ecology.

Front. Ecol. Evol. 8:580447. doi: 10.3389/fevo.2020.580447

\section{A Trait-Based Approach to Self-Organized Pattern Formation in Ecology}

\author{
Xiaoli Dong* \\ Department of Environmental Science and Policy, University of California, Davis, Davis, CA, United States
}

Significant effort in the study of self-organized pattern formation has focused on the physical conditions of the ecosystem. But what about the organisms involved? Can just any species form patterns or are certain traits required? I performed a metadata analysis of pattern-forming species in various patterned ecosystems worldwide and analyzed trait values and other biological characteristics to address this question. Results indicate that some species are more likely to form patterns than others, as a result of their possessing a portfolio of traits conducive to pattern formation. There is a conservation of these traits among species forming vegetation patterns across regions of the world. The degree of conservation is high when regular patterns are formed by the mechanism of scale dependent feedbacks. In contrast, when regular patterns arise from intraspecific competition, cross-site variation among pattern-forming species becomes high. Understanding evolutionary implications of pattern formation can be enhanced by this trait-based approach, a perspective that has been lacking to date.

Keywords: biogeography, competition, regular patterns, self-organization, trait

\section{INTRODUCTION}

Self-organized regular patterns are periodic distributions of features that share a characteristic cluster size, as opposed to random configurations of heterogeneously sized clusters. These patterns occur worldwide, with significant ecosystem consequences (Rietkerk and van de Koppel, 2008). The widely embraced mechanism for self-organization is scale-dependent feedback (SDF), induced by resource-limitation or physical stress in the environment (Rietkerk and van de Koppel, 2008), e.g., patterned vegetation in arid and semi-arid regions (Deblauwe et al., 2008). Additionally, intraspecific territorial competition also has been proposed to contribute to regular pattern formation (Pringle and Tarnita, 2017).

Much previous work on pattern formation has focused on environmental constraints; i.e., an understanding of what environmental conditions support pattern formation. A global analysis of patterned vegetation showed that regular patterning appears in a predictable way under specific environmental conditions: e.g., evapotranspiration is $>$ three times as high as rainfall, annual precipitation is $<400 \mathrm{~mm}$, and landscape slope is $<2 \%$, among other constraints (Deblauwe et al., 2008, 2012). Although these studies acknowledge that interactions among organisms may trigger and affect pattern formation, our understanding of biological components remains limited. Identity of organisms in biological pattern formation is largely "invisible." Given requisite environments, are all plant species adapted to those environmental conditions equally likely to form regular patterns? 
Or are there certain traits that might either enhance or reduce the likelihood for certain species to participate?

When regular patterns are formed via SDF, species vested with traits that enhance the constituent processes of SDF will be more likely to participate. That is, while there may not be traits required in pattern formation, certain traits are conducive to pattern formation. A motivating example is patterned vegetation. We expect species more conducive to pattern formation to have high water-capture capacity (e.g., traits to induce more stem flow and/or to laterally intercept more runoff). This would simultaneously intensify local positive feedback and negative feedback at longer distance. Therefore, I hypothesize that traits reinforcing steps in the SDF mechanism will be differentially prevalent in patterned vegetation. From this hypothesis, I derive the following predictions (Figure 1): (P1a) in different regions of different species pools but with the same regular patterning, I predict a conservation of traits: while species identities may vary widely, the probability density distribution of trait values will be similar across regions; $(\mathbf{P 1 b})$ in a region ideal for pattern formation, but devoid of regular patterns, I predict that pattern formation is constrained by the species pool-a lack of species with traits conducive to patterning; and (P1c) in a region with a homogeneous species pool, I predict a high degree of conservation of pattern-forming species across regular patterns, i.e., a relatively fixed subset of species showing up where pattern form. The probability density distribution of relevant traits would be similar among patterns, and distinctively different from the trait distribution of the community outside the patterns in that region.

Long-standing literature in entomology and animal behavior suggests competition for space by mobile organisms can also produce regular patterns (Thorne and Haverty, 1991). Although these previously nonintersecting literatures have recently collided in debates over pattern genesis that pit them as competing mechanisms, most recent research suggests that they may not be mutually exclusive (Pringle and Tarnita, 2017; Tarnita et al., 2017). SDF by sessile/semi-sessile organisms relies on diffusion of mediating resources (e.g., water) to create a gradient, which organizes the pattern-forming agents, and competition by mobile species forms the pattern via direct interaction or indirect interference between organisms (Tarnita et al., 2017). For example, aggressive interference competition between conspecific colonies for nesting resources results in overdispersed patterns, a territorial behavior ubiquitous in termites (Thorne and Haverty, 1991). As long as environmental conditions are met, most termite species possessing relevant competitive behavioral traits will form patterns. Similarly, to successfully reproduce the spatial periodicity of mima mounds, models only need to include two generic behavioral traits of gophers (Gabet et al., 2014): (1) gophers build burrows in seasonally saturated soils for refuges, and (2) they transport burrow tailings to topographic highs and thereby move materials away from the wetter topographic lows (Cox and Allen, 1987). Therefore, if a regular pattern is formed primarily by competition among mobile organisms, we expect a relative low degree of conservation of patternforming species, that is, species may vary greatly across even near-by sites (P2).
To evaluate these predictions, I did a thorough metadata analysis of literature to compile a list of pattern-forming species (Supplementary Methods and Supplementary Table 1), collected various trait data (Supplementary Tables 2, 3), and analyzed phylogenetic relationships (Supplementary Figures 1-3). It is worth noting that I assume "dominant species" (criteria for "dominant species" is provided in Supplementary Methods) observed in formed patterns as "pattern-forming species." It is likely that the actual pattern-forming species are only a subset of the dominant group. I focused on five types of regular patterns with varying degree of emphasis: patterned vegetation, fairy circles, mima mounds, termite mounds, and patterned mussel beds. Self-organized regular patterns also have been recorded in geomorphology, such as patterned peatlands (Eppinga et al., 2009), ridge-slough patterns in the Everglades (Florida, United States) (Larsen and Harvey, 2010), sorted circles in Arctic landscapes (Kessler and Werner, 2003) etc. In those patterns, morphodynamics-interactions between fluid flow, sediments, and morphology_often play a more dominant role than do biological organisms (Murray et al., 2014). Formation of many geomorphic regular patterns do not involve biological processes (Murray et al., 2014). Since this study is intended to demonstrate the role of biological characteristics of patternforming agents, I selected five types of regular patterns in which organisms obviously play a critical role. Additionally, self-organization can form non-regular patterns (Schoelynck et al., 2012; Zhao et al., 2019). For non-regular patterns, however, it is often not obvious that the patterns are self-organized, therefore, they require case-by-case investigations. As such, case studies on self-organized non-regular patterns are still limited. Furthermore, mechanisms other than SDF have been shown to form regular patterns, e.g., competition (Barbier et al., 2008; Pringle and Tarnita, 2017) and phase separation (Liu et al., 2013). In current ecological literature, however, the vast majority of patterns are formed by SDF (Rietkerk and van de Koppel, 2008). While a thorough study of the relationship between biological trait on self-organized patterns formed by an array of different mechanism across a gradient of systems ranging from biological to geological would be ideal, here, I focused specifically on self-organized, regular patterns formed by SDF dominated by biological processes to introduce and inspire a novel, general biological perspective of ecological pattern formation.

\section{TRAITS OF ORGANISMS IN PATTERN-FORMING SYSTEMS}

Meta-analysis results in 69 plant species dominating regularly patterned vegetations (RPV), 7 grass species for fairy circles, 36 ant/termite species for patterned termite mounds, 11 gopher species for mima mounds, and 1 mussel species for patterned mussel beds (Figure 2). First, I use RPVs as a primary example and discuss traits that prevail across pattern-forming plant species-resource capture, root structure, and reproduction mode. I noted several important characteristics of patternforming plant species for RPVs (Figure 2): (1) species varies 


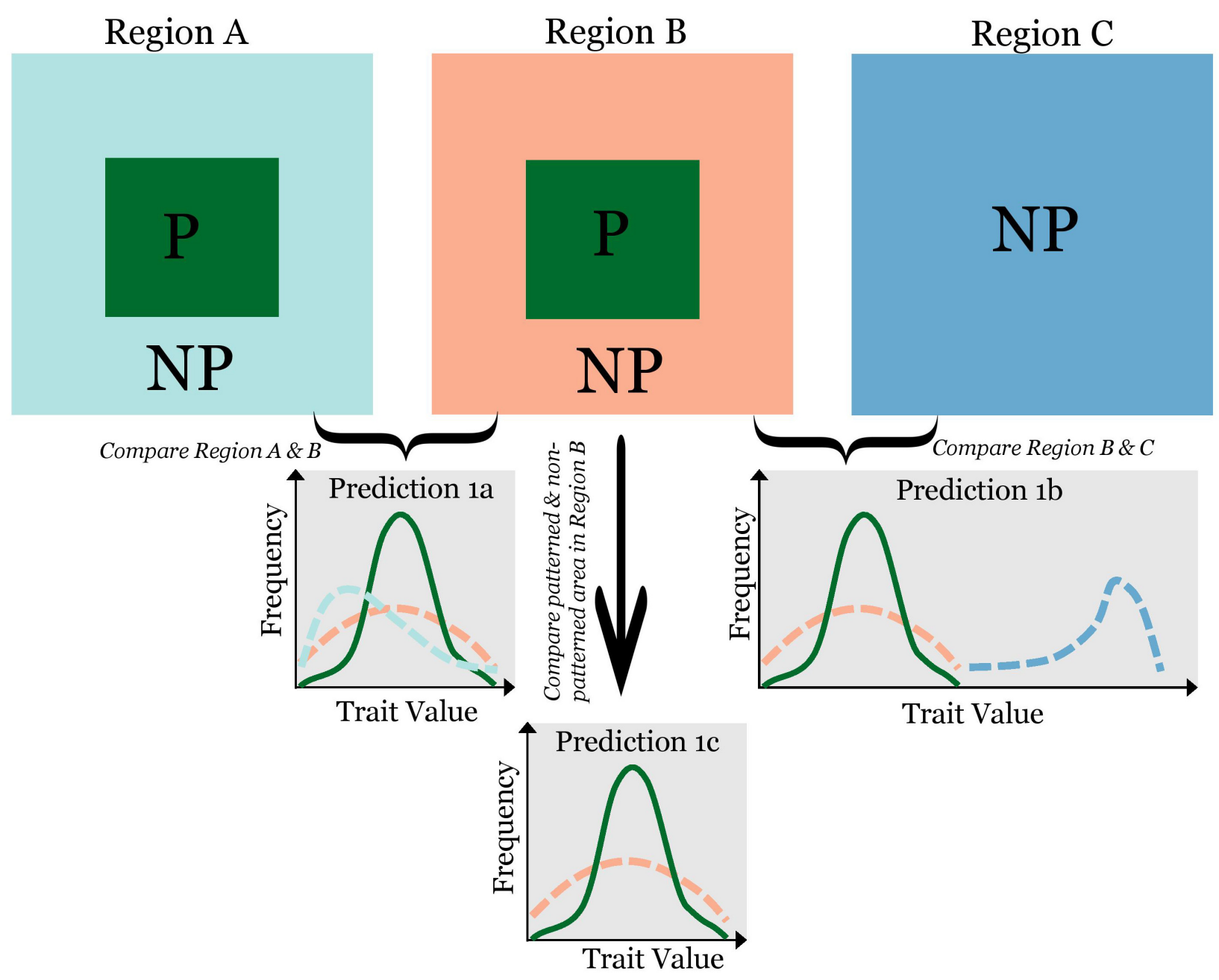

FIGURE 1 | A framework to test hypotheses on the biological constraint of pattern formation using a trait-based approach. "P": patterned and "NP": non-patterned. Solid dark green lines (correspond to the dark-green area of labeled with " $P$ " in Region $\mathbf{( A , B ) ~ s h o w ~ t h e ~ f r e q u e n c y ~ d i s t r i b u t i o n ~ o f ~ a ~ p a t t e r n - f o r m i n g ~ t r a i t ~ w i t h i n ~ t h e ~}$ pattern, and dashed-lines show the frequency distribution of the same trait from the area outside the pattern (the color of lines corresponds to the color of areas). If traits play a role in pattern formation, the following predictions are derived: (1) in two regions that have different trait frequency distributions, we will observe similar frequency distribution of traits from patterned areas in the two regions (Prediction 1a); (2) comparing Region (B,C), with all environmental conditions the same, but one with regular patterns and another without, we expect the trait distribution in Region (C) to be very different from that in Region (B) (Prediction 1b); and (3) in the same region, we expect the frequency distribution of traits for species within and outside the pattern to be different (Prediction 1c).

greatly among continents, reflecting constraints of the species pool; (2) Acacia is the only genus found across three continents as the pattern-forming species, and it is the genus with the largest number of pattern-forming plants; and (3) Acacia aneura dominates in almost all RPVs in Australia, while pattern-forming species varies slightly more across regions in Africa.

\section{Water Capture}

In forming RPVs by SDF, if the long-distance negative feedback is not strong enough to suppress the germination of seeds falling in the bare area, seedlings will establish and fill bare areas. One way that will intensify negative feedback is by enhancing water capturing capacity such that little runoff is released to downslope bare ground. As such, we expect that plants with traits enhancing water capture are more likely to dominate RPVs. A total of
18 perennial herbaceous species were identified to dominate RPVs worldwide, and $>70 \%$ form tussocks (Supplementary Table 2), presumably higher than dryland grasses elsewhere. Tussock grasses have low stem flow and throughfall and their large basal area is instrumental in capturing runoff (Pressland and Lehane, 1982; Domingo et al., 1998). Another piece of evidence is from Mulga-banded vegetation in Australia. Mulga is recorded in many regions of Australia but the dominant species across all sites is Acacia aneura (Miller et al., 2002), even though there are $\sim 1,000$ Acacia species in Australia (Maslin and Pedley, 1988). The near-vertical architecture of $A$. aneura branches, stems, and phyllodes promotes efficient channeling of rainfall to stem bases (Slatyer, 1965; Miller et al., 2002). As a result, a large proportion of intercepted rainfall is delivered as stemflow (Pressland, 1973; Dunkerley and Booth, 1999), significantly 


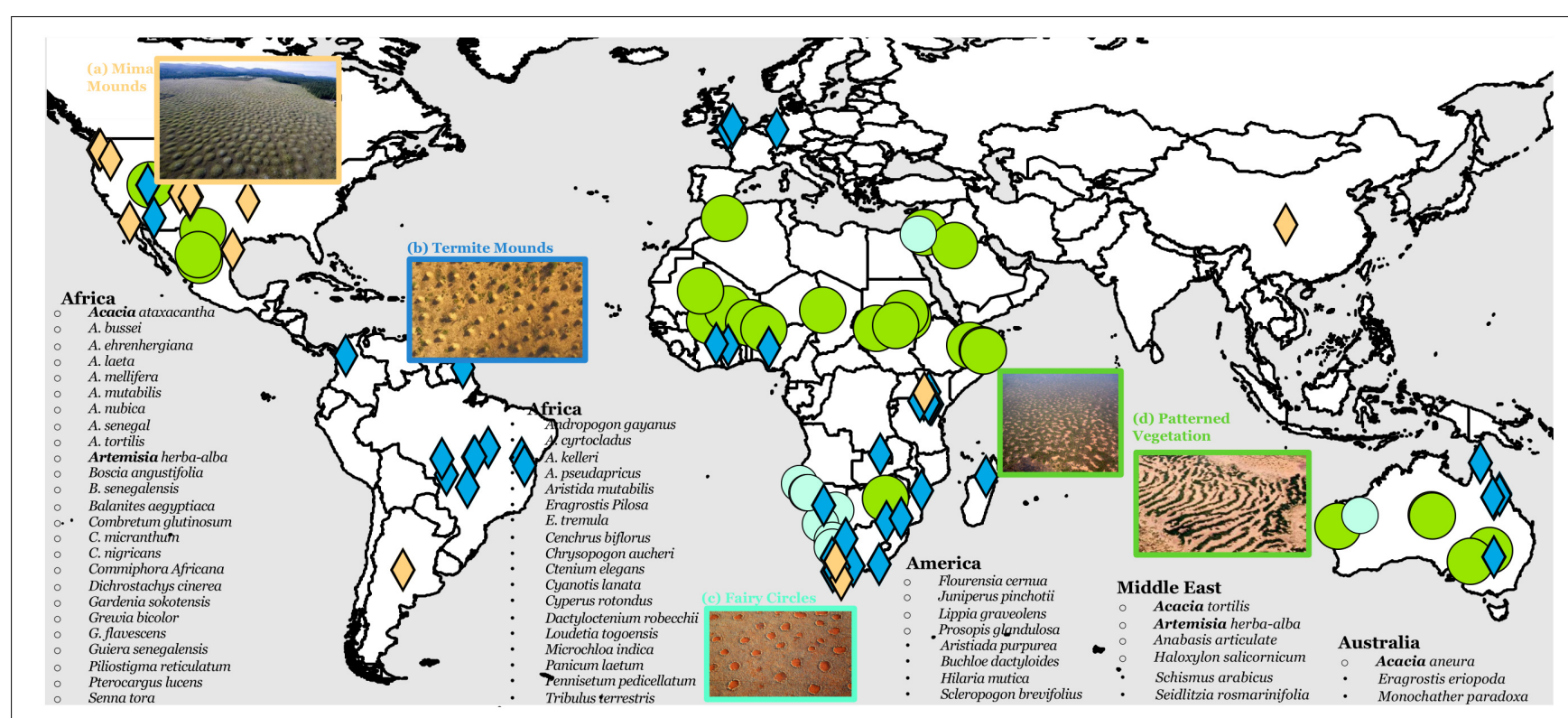

FIGURE 2 | Distribution of self-organized, regular ecological patterns-(A) mima mounds, (B) termite mounds, (C) fairy circles, and (D) patterned vegetation around the world and pattern-forming species associated with patterned vegetation on each continent. Open bullet point indicates dominant woody species and solid bullet points are dominant herbaceous species in the patterns. Generic names that appear on more than one continent are in bold.

augmenting the amount of water available to roots (e.g., $25 \mathrm{~mm}$ of rainfall can rise to $140 \mathrm{~mm}$ of water delivered to the rooting zone of A. aneura; Kerle, 1995). These traits enhance plant water capture both horizontally and vertically, intensifying SDF.

A high percent of species with high water capturing capacity increases water capture at the patch scale. The amount of water received by the vegetated patch can reach $3 \sim 4$ times actual rainfall (Bromley et al., 1997). Empirical studies have established that vegetated patches in RPVs can absorb almost all surface flow, thereby eliminating most runoff to downslope bare ground (Tongway and Ludwig, 1990).

\section{Root Structure}

Dryland plants acquire water with either deep roots or shallow, extensive lateral roots (Schwinning and Hooten, 2009). Deep roots with access to deep soil water attenuate water limitation and to some degree bypass the mechanism of SDF (as long as groundwater is not limited). Hence, plants with deep roots and reliable groundwater supply are more likely to establish in otherwise surface dry areas, distorting regular patterning. I was able to gather descriptions of root structure for 25 out of 38 pattern forming woody plants (Supplementary Table 3), and $>90 \%$ are characterized by laterally extensive, shallow roots, and unlike roots of phreatophytes. Shallow roots limit water access to surface water. An extensive shallow lateral root system creates massive root channels in soil surface layers, which offers rapid by-pass routing during rainfall events and increases soil hydraulic conductivity, hence infiltration rate and water capturing capacity (Bromley et al., 1997). For example, a 5$\mathrm{m}$ A. aneura, the major pattern-formation species in Mulga, has abundant lateral roots that are confined within the top $20 \mathrm{~cm}$ of soil and extend up to $13 \mathrm{~m}$ from the base of the tree
(Anderson and Hodgkinson, 1997). At the same site, Eucalyptus populnea, whose roots enter fractured rock for an additional water source, is scattered in both bare and vegetated patches (Anderson and Hodgkinson, 1997). These examples suggest that the likelihood of different species to form patterns varies, based on differences in their traits, in this case root structure.

Environmentally, shallow soils have been shown to enhance pattern formation (Penny et al., 2013). Disproportionally high abundance of a shallow root structure could be confounded by shallow soil depth above the impermeable root limiting layer and/or by soil porosity. I found of the 34 sites where soil depth information is available, $>50 \%$ have deep soil layers $(>200 \mathrm{~cm})$. However, almost all these deep soil sites are dominated by species with laterally extensive, shallow $(<50 \mathrm{~cm})$ roots (Supplementary Table 3), suggesting that the large proportion of patternforming species being shallow-rooted is not likely a response to shallow soils.

\section{Reproduction}

Mode of reproduction influences morphometrics. Genetic analysis of Mulga populations show that morphometrics of phyllodes (the angle of which influences water capture) is heritable and discontinuous (Andrew et al., 2003), which suggests that intermediate or recombinant forms either rarely survive selection, or are not produced due to reproductive barriers. Various degrees of apomixis are observed in all Mulga species, which reduces the frequency of sexual reproduction (Andrew et al., 2003). Major pattern-forming species in Africa, e.g., Combretum micranthum, Guiera senegalensis, Pleuraphis murtica, rely on vegetative reproduction (Thompson et al., 2008). These modes of reproduction increase the conservation of traits conducive to pattern formation. 


\section{TRAIT AND BIOGEOGRAPHY: TESTING PREDICTIONS}

A trait-based approach can be integrated with previous work highlighting the environmental conditions for pattern formation (Deblauwe et al., 2008). Environmental requirements are met in geographically dispersed regions characterized by different species pools. These natural experiments highlight the role of traits. First, the woody layer of many RPVs across different continents-Australia, Middle East, Africa-is dominated by Acacia, although different Acacia species participate across continents (Figure 2). With $>1300$ species in its genus, only ten Acacia species dominate RPVs worldwide. All ten species have an extensive lateral, shallow root system. Specifically, A. aneura dominates almost all RPVs in Australia, Combretum glutinosum, C. micranthum, and Combretum nigricans are the dominant species in a vast majority of RPVs in northwestern Africa, including Niger, Burkina Faso, Mali, Mauritania, Senegal and Nigeria (Figure 2), and Mytilus edulis is the sole species that forms patterned mussel beds worldwide. In Australia, ten other Acacia species often coexist in Mulga (referred to as the Mulga Group; Miller et al., 2002). Assuming that traits are more conserved among close relatives, I performed phylogenetic analysis of the Mulga group and 31 most common Acacia species outside of Mulga in Australia. Results show that the Mulga group is evolutionarily distinctively closely related as a cluster (Supplementary Figure 3). Similarly, phylogenetic analysis shows that C. glutinosum, C. micranthum, and C. nigricans forming RVPs in Africa are also closely related. These results provide evidence of conservation of pattern-forming species in the same region (P1c) and conservation of traits across RPVs in different regions $(\mathbf{P} 1 \mathbf{a})$.

A second example highlighting the role of traits is the absence of RPVs in places that seem otherwise optimal. For example, as predicted by the model that synthesized environmental requirements of RPVs worldwide (Deblauwe et al., 2008), a large part of the hot deserts in North America (Mojave, Sonoran, and Chihuahua Deserts) satisfies the environmental prerequisites for patterning, yet RPVs have been rarely reported there. An exception is a small region in the Chihuahua Desert (Cornet et al., 1992; McDonald et al., 2009). While it is likely that the scarcity of RPVs in these deserts is caused by environmental conditions not captured by the model by Deblauwe et al. (2008), biological constraints-e.g., lack of species with traits prone to pattern formation-may also play a role. In the Mojave Desert, nonsucculent trees are nearly all phreatophytic, with roots obtaining water from a permanent groundwater supply (Schwinning and Hooten, 2009). In the Chihuahua Desert, ten out of 11 common shrubs have deep root systems reaching groundwater (Gibbens and Lenz, 2001). Finally, a large proportion of common woody plants in the Sonoran Desert (Turner and Brown, 1978) is characterized by taproots $(>5 \mathrm{~m})$. In these deserts, Larrea tridentata is very common, yet not found in the few RPVs in the region. This might have to do with traits discussed previously. L. tridentata has extensive roots, vertically $(>5 \mathrm{~m})$ and laterally $(\sim 4.5 \mathrm{~m})$ (Gibbens and Lenz, 2001). Deep roots accessing groundwater reduce the effectiveness of SDF. Additionally, lateral roots of Larrea tend to avoid spatial overlap with other plants (Brisson and Reynolds, 1994), resulting in a large inter-plant gap for runoff. This would reduce the water capture capacity by plants, further weakening SDF. Larrea lives for centuries, at some sites, >1,000 years. Regular patterns formed by Larrea would have low flexibility to adjust to climatic changes. The case of North America hot deserts might indicate evidence for the effect of lack of species with conducive traits on forming patterns in locations otherwise suitable for patterning (P1b).

While SDF is widely embraced as a general mechanism for pattern formation by sessile/semi-sessile organisms (e.g., plants, mussels), regular patterns such as termite mounds and mima mounds more likely form by intraspecific competition. I found large site-to-site variation in pattern-forming species for regular termite mound patterns and mima mounds (Supplementary Table 4), e.g., mima mounds in the seven states in the United States are formed by six gopher species (Supplementary Table 4) and nine areas with abundant regular termite mounds in Brazil are formed by seven termite species (for both gopher and termite mound patterns, often a single species dominates one pattern/site). These indicate a much lower conservation of pattern-forming species among sites or much higher robustness to form patterns than by sessile/semi-sessile organisms against environment conditions, contrasting to RPVs (e.g., A. aneura is the dominant species in almost all RPVs in Australia, regardless of $\sim 1,000$ similar Acacia species available there) (P2). This may imply a lower requirement for specific traits in pattern formation by competition of mobile organisms, since similar behaviors can be depicted in different environments.

\section{BEYOND TRAITS}

Pattern formation by SDF likely requires certain biological conditions-beyond species traits-such as relatively low biodiversity and relatively weak competition. The bare ground in patterns represents unoccupied niches. High species diversity renders it less likely to have unoccupied niches and increases variation of interactions and interaction strengths, contrary to the homogeneous interactions assumed by the SDF model. I found extreme low plant diversity in landscapes of fairy circles in Namibia, Israel, and Australia. A landscape of fairy circles in Namibia consists of only 2 3 Stipagrostis grasses. Patterned mussel beds are monospecific, consisting of a single species of Mytilus edulis. Within vegetated patches in RPVs, facilitation, as opposed to competition, is supposed to be the dominant force. Strong intra- and inter-specific competition likely increases the spacing among individual plants (Phillips and Macmahon, 1981), which will result in greater surface runoff from vegetated to bare patches. This weakens both local positive feedback and long-distance negative feedback.

\section{FUTURE PERSPECTIVES}

It is unlikely that the literature surveyed here captures all of the periodic patterns worldwide. Many patterns might be cryptic in 
some way-have a fine resolution (e.g., patterns of herbaceous species have patch sizes much finer than those of woody plants), a small spatial extent, or be undiscovered in remote locations. Additionally, spatial patterning or the lack of it might be caused by legacy effects, which are ubiquitous in ecology since transient periods could be long (Hastings et al., 2018). While I strive to test a priori predictions derived from pattern-forming mechanisms, post-hoc interpretations are invoked in several places throughout this study in that trait data are limited. To rigorously test whether a trait is conducive to pattern formation, we would need data on that trait for all common species in the area and to then compare the frequency of that trait within pattern forming species to that among non-pattern-forming ones. Collecting such a dataset would be a formidable challenge. Furthermore, the tendency of a particular species to form patterns likely results from a portfolio of traits. A rigorous test would also require controlling all environmental conditions (e.g., climate, disturbance history, and physical variables) so that the effect of environmental conditions and biological traits on pattern occurrence can be disentangled. Finding such geographic regions could be challenging.

Unlike pattern formation in physical systems (e.g., Coco and Murray, 2007), the agents forming self-organized ecological patterns are organisms, with traits and behaviors derived from evolution (Dong and Fisher, 2019; De Jager et al., 2020). Hence, regardless of the overarching role of physical environments, I argue that a better understanding of the biological components of ecological pattern formation will provide insights into a set of significant questions: e.g., How do evolutionary processes relate to ecological pattern formation? If a species with a certain portfolio of traits is more likely to be involved in pattern formation, will these traits be enhanced over time? If yes, how is that realized via natural selection? Is there a tendency for patterns to emerge over evolutionary time? Answers to these and other

\section{REFERENCES}

Anderson, V. J., and Hodgkinson, K. C. (1997). Grass-mediated capture of resource flows and the maintenance of banded Mulga in a semi-arid woodland. Autra. J. Bot. 45, 331-342. doi: 10.1071/BT96019

Andrew, R. L., Miller, J. T., Peakell, R., Crip, M. D., and Bayer, R. J. (2003). Genetic, cytogenetic and morphological patterns in a mixed mulga population: evidence for apomixis. Aust. Syst. Bot. 16, 69-80. doi: 10.1071/SB01043

Barbier, N., Couteron, P., Lefever, R., Deblauwe, V., and Lejeune, O. (2008). Spatial decoupling of facilitation and competition at the origin of gapped vegetation patterns. Ecology 89, 1521-1531. doi: 10.1890/07-0365.1

Brisson, J., and Reynolds, J. F. (1994). The effect of neighbors on root distribution in a creosotebush (Larrea tridentata) population. Ecology 75, 1693-1702. doi: $10.2307 / 1939629$

Bromley, J., Brouwer, J., Barker, A. P., Gaze, S. R., and Valentine, C. (1997). The role of surface water redistribution in an area of patterned vegetation in a semiarid environment, south-west Niger. J. Hydrol. 198, 1-29. doi: 10.1016/S00221694(96)03322-7

Coco, G., and Murray, A. B. (2007). Patterns in the sand: from forcing templates to self-organization. Geomorphology 91, 271-290. doi: 10.1016/j.geomorph.2007. 04.023

Cornet, A. F., Montana, C., Delhoume, J. P., and Lopez-Portillo, J. (1992). "Water flows and the dynamics of desert vegetation stripes," in Landscape Boundaries, eds A. J. Hansen and F. DiCastri (New York, NY: Springer), 327-345. doi: 10.1007/978-1-4612-2804-2_16 evolutionary questions await future work on biological aspects of ecosystem pattern formation.

\section{DATA AVAILABILITY STATEMENT}

All datasets presented in this study are included in the article/Supplementary Material.

\section{AUTHOR CONTRIBUTIONS}

XD conceived the idea, collected the data, analyzed the data, and wrote the manuscript.

\section{FUNDING}

The work was supported by startup fund by University of California, Davis to XD.

\section{ACKNOWLEDGMENTS}

The author is grateful for the stimulating discussions with Evan B. Goldstein. The manuscript was greatly improved by comments from Evan B. Goldstein, Stuart G. Fisher, Susan P. Harrison, and reviewers.

\section{SUPPLEMENTARY MATERIAL}

The Supplementary Material for this article can be found online at: https://www.frontiersin.org/articles/10.3389/fevo.2020. 580447/full\#supplementary-material

Cox, G. W., and Allen, D. W. (1987). Soil translocation by pocket gophers in a mima moundfield. Oecologia 72, 207-210. doi: 10.1007/BF00379269

De Jager, M., van de Koppel, J., Weerman, E. J., and Weissing, F. J. (2020). Patterning in mussel beds explained by the interplay of multilevel selection and spatial self-organization. Front. Ecol. Evol. 8:7. doi: 10.3389/fevo.2020. 00007

Deblauwe, V., Barbier, N., Couteron, P., Lejeune, O., and Bogaert, J. (2008). The global biogeography of semi-arid periodic vegetation patterns. Glob. Ecol. Biogeogr. 17, 715-723. doi: 10.1111/j.1466-8238.2008.00413.x

Deblauwe, V., Couteron, P., Bogaert, J., and Barbier, N. (2012). Determinants and dynamics of banded vegetation pattern migration in arid climates. Ecol. Monogr. 82, 3-21. doi: 10.1890/11-0362.1

Domingo, F., Sanchez, G., Moro, M. J., Brenner, A. J., and Puigdefabregas, J. (1998). Measurement and modelling of rainfall interception by three semiarid canopies. Agric. For. Meteorol. 91, 275-292. doi: 10.1016/S0168-1923(98) 00068-9

Dong, X., and Fisher, S. G. (2019). Ecosystem spatial self-organization: free order for nothing?? Ecol. Complex. 38, 24-30. doi: 10.1016/j.ecocom.2019.01.002

Dunkerley, D. L., and Booth, T. L. (1999). Plant canopy interception of rainfall and its significance in a banded landscape, arid western New South Wales. Australia. Water Resour. Res. 35, 1581-1586. doi: 10.1029/1999WR90 0003

Eppinga, M. B., de Ruiter, P. C., Wassen, M. J., and Rietkerk, M. (2009). Nutrients and hydrology indicate the driving mechanisms of peatland surface patterning. Am. Nat. 173, 803-818. doi: 10.1086/598487 
Gabet, E. J., Perron, J. T., and Johnson, D. L. (2014). Geomorphology Biotic origin for Mima mounds supported by numerical modeling. Geomorphology 206, 58-66. doi: 10.1016/j.geomorph.2013.09.018

Gibbens, R. P., and Lenz, J. M. (2001). Root systems of some chihuahuan desert plants. J. Arid Environ. 49, 221-263. doi: 10.1006/jare.2000.0784

Hastings, A., Abbott, K. C., Cuddington, K., Francis, T., Gellner, G., Lai, Y.-C., et al. (2018). Transient phenomena in ecology. Science 361:eaat6412. doi: 10.1126/ science.aat6412

Kerle, J. A. (1995). “Mulga-Wanari,” in Uluru, Kata-Tjuta \& Watarrka (Ayers Rock, the Olgas \& Kings Canyon, Northern Territory), ed. T. Lee (Sydney: University of New South Wales Press), 74-76.

Kessler, M. A., and Werner, B. T. (2003). Self-organization of sorted patterned ground. Science 299, 380-383. doi: 10.1126/science.1077309

Larsen, L. G., and Harvey, J. W. (2010). Modeling of hydroecological feedbacks predicts distinct classes of landscape pattern, process, and restoration potential in shallow aquatic ecosystems. Geomorphology 126, 279-296. doi: 10.1016/j. geomorph.2010.03.015

Liu, Q.-X., Doelman, A., Rottschafer, V., de Jager, M., Herman, P. M. J., Rietkerk, M., et al. (2013). Phase seperation explains a new class of self-organized spatial patterns in ecological systems. Proc. Natl. Acad. Sci. U.S.A. 110, 11905-11910. doi: $10.1073 /$ pnas. 1222339110

Maslin, B. R., and Pedley, L. (1988). Patterns of distribution of Acacia in Australia. Austr. J. Bot. 36, 385-393. doi: 10.1071/BT9880385

McDonald, A. K., Kinucan, R. J., and Loomis, L. E. (2009). Ecohydrological interactions within banded vegetation in the northeastern Chihuahuan Desert. USA. Ecohydrology 2, 66-71. doi: 10.1002/eco

Miller, J. T., Andrew, R. A., and Maslin, B. R. (2002). Towards an understanding of variation in the Mulga complex (Acacia aneura and relatives). Conserv. Sci. Western Austr. 4, 19-35.

Murray, A. B., Goldstein, E. B., and Coco, G. (2014). The shape of patterns to come: from initial formation to long-term evolution. Earth Surface Process. Landf. 39, 62-70. doi: 10.1002/esp.3487

Penny, G., Daniels, K. E., and Thompson, S. E. (2013). Local properties of patterned vegetation: quantifying endogenous and exogenous effects. Philos. Trans. R. Soc. A 371, 1-27. doi: 10.1098/rspa.00000000

Phillips, D. L., and Macmahon, J. A. (1981). Competition and spacing patterns in desert shrubs. J. Ecol. 69, 97-115. doi: 10.2307/2259818

Pressland, A., and Lehane, K. (1982). Runoff and the ameliorating effect of plant cover in the mulga communities of south western Queensland. Rangel. J. 4, 16-20. doi: $10.1071 /$ rj9820016

Pressland, A. J. (1973). Rainfall partitioning by an arid woodland (Acacia aneura F. Muell.) In South-Western Queensland. Austr. J. Bot. 21, 235-245. doi: 10.1071/ BT9730235
Pringle, R. M., and Tarnita, C. E. (2017). Spatial self-organization of ecosystems: integrating multiple mechanisms of regular-pattern formation. Annu. Rev. Entomol. 62, 359-377. doi: 10.1146/annurev-ento-031616-035413

Rietkerk, M., and van de Koppel, J. (2008). Regular pattern formation in real ecosystems. Trends Ecol. Evol. 23, 169-175. doi: 10.1016/j.tree.2007.10.013

Schoelynck, J., De Groote, T., Bal, K., Vandenbruwaene, W., Meire, P., and Temmerman, S. (2012). Self-organised patchiness and scale-dependent biogeomorphic feedbacks in aquatic river vegetation. Ecography 35, 760-768. doi: 10.1111/j.1600-0587.2011.07177.x

Schwinning, S. U., and Hooten, M. M. (2009). "mojave desert root systems," in The Mojave Desert: Ecosystem Processes and Sustainability, ed. R. H. Webb (Nevada: University of Nevada Press), 252-277.

Slatyer, R. (1965). Measurements of precipitation interception by an arid zone plant community (Acacia aneura F. Muell.). Arid Zone Res. 25, 181-192.

Tarnita, C. E., Bonachela, J. A., Sheffer, E., Guyton, J. A., Coverdale, T. C., Long, R. A., et al. (2017). A theoretical foundation for multi-scale regular vegetation patterns. Nature 541, 398-401. doi: 10.1038/nature20801

Thompson, S., Katul, G., and McMahon, S. M. (2008). Role of biomass spread in vegetation pattern formation within arid ecosystems. Water Resour. Res. 44, 1-13. doi: 10.1029/2008WR006916

Thorne, B. L., and Haverty, M. I. (1991). A review of intracolony, intraspecific, and interspecific agonism in termites. Sociobiology 19, 115-145.

Tongway, D. J., and Ludwig, J. A. (1990). Vegetation and soil patterning in semiarid mulga lands of Eastern Australia. Austr. J. Ecol. 15, 23-34. doi: 10.1111/j. 1442-9993.1990.tb01017.x

Turner, M., and Brown, D. E. (1978). "Sonoran desertscrub," in Biotic Communities of the American Southwest-United States and Mexico, ed. D. Brown (Tucson, AZ: University of Arizona), 181-221.

Zhao, L.-X., Xu, C., Ge, Z.-M., van de Koppel, J., and Liu, Q.-X. (2019). The shaping role of self-organization: linking vegetation patterning, plant trait and ecosystem functioning. Proc. R. Soc. B Biol. Sci. 286:20182859. doi: 10.1098/ rspb.2018.2859

Conflict of Interest: The author declares that the research was conducted in the absence of any commercial or financial relationships that could be construed as a potential conflict of interest.

Copyright $\odot 2020$ Dong. This is an open-access article distributed under the terms of the Creative Commons Attribution License (CC BY). The use, distribution or reproduction in other forums is permitted, provided the original author(s) and the copyright owner(s) are credited and that the original publication in this journal is cited, in accordance with accepted academic practice. No use, distribution or reproduction is permitted which does not comply with these terms. 